\title{
The effects of anaesthesia on cerebral oxygenation and cognitive function in carotid endarterectomy
}

Kuzkov VV, Obraztsov MY, Ivashchenko OY, Ivashchenko NY, Gorenkov VM, Kirov MY

Department of Anaesthesiology and Intensive Care Medicine, Northern State Medical University, Arkhangelsk, Russian Federation

\section{Background \& Goal}

A transient deterioration of cerebral haemodynamics and oxygenation during CEE might involve both hemispheres of the brain and affects postoperative cognition. ${ }^{1}$ Despite some benefits of regional blocks, the majority of procedures of carotid endarterectomy (CEE) are performed under general anaesthesia. Surprisingly, the studies comparing the effects of sevoflurane and propofol on postoperative mental state in CEE are scarce and controversial. ${ }^{2,3}$ While propofol possesses some anti-inflammatory properties, volatile anaesthetics can interfere with cerebral blood flow and reperfusion-ischaemia injury via the mechanism of pre- and postconditioning. The goal of this study was to assess the effects of the anaesthetics on the perioperative cerebral oxygenation and cognitive functions in CEE.

\section{Methods}

The study and informed consent were approved by the Ethical Committee of the Northern State Medical University. Forty patients (males only; $n=40$, age 63 (59-68) yrs, weight 80 (70-90) $\mathrm{kg}$ ) who underwent elective CEE were included into a prospective study and randomised to two groups receiving either total intravenous anaesthesia (TIVA group, $n=20$; propofol + fentanyl) or the volatile induction and maintenance of anaesthesia (VIMA group, $n=20$, sevoflurane + fentanyl). All patients were operated using temporary carotid bypass. Invasive arterial pressure (AP), gas exchange, and cerebral tissue oxygen saturation $\left(\mathrm{SctO}_{2}\right.$, ForeSight, CAsMed, USA) over frontal region for ipsilateral $\left(\mathrm{SctO}_{2 \mathrm{IPSI}}\right)$ and contralateral $\left(\mathrm{SctO}_{2 \mathrm{CONTR}}\right)$ hemispheres were registered during the surgery and up to $20 \mathrm{hrs}$ of the postoperative period. The cognitive changes were assessed at $12 \mathrm{hrs}$ before as well as on Days 1 and 5 after CEE by blinded investigator using Montreal Cognitive Assessment score (MoCA).

Data are presented as median $\left(25-75^{\text {th }}\right.$ percentiles). Intergroup comparison was provided with Mann-Whitney $U$-test and correlation analysis with Spearman's coefficient (rho). $P$ value below 0.05 was regarded as statistically significant.

\section{Results \& Discussion}

There were no significant baseline differences between groups (Table 1). We did not ob-

\begin{tabular}{|c|c|c|c|}
\hline Parameter & TIVA & VIMA & $p$ \\
\hline Age, yrs & $64(61-70)$ & $64(58-67)$ & 0.62 \\
\hline Weight, kg & $80(71-94)$ & $78(70-86)$ & 0.70 \\
\hline Side of CEE (L / R) & $11 / 9$ & $10 / 10$ & 0.75 \\
\hline Duration of surgery, $\mathrm{min}$ & $116(103-155)$ & $110(96-128)$ & 0.18 \\
\hline Clamping time, $\min ^{*}$ & $4.0(4.0-5.0)$ & $4.0(3.0-5.8)$ & 0.45 \\
\hline Length of ICU stay, hrs & $21(21-22)$ & $22(21-22)$ & 0.72 \\
\hline Length of hospital stay, days & $14(11-18)$ & $12(11-13)$ & 0.30 \\
\hline Ipsilateral stenosis, \% & $80(73-85)$ & $80(75-85)$ & 0.66 \\
\hline Contralateral stenosis, \% & $54(40-75)$ & $58(39-61)$ & 0.75 \\
\hline
\end{tabular}
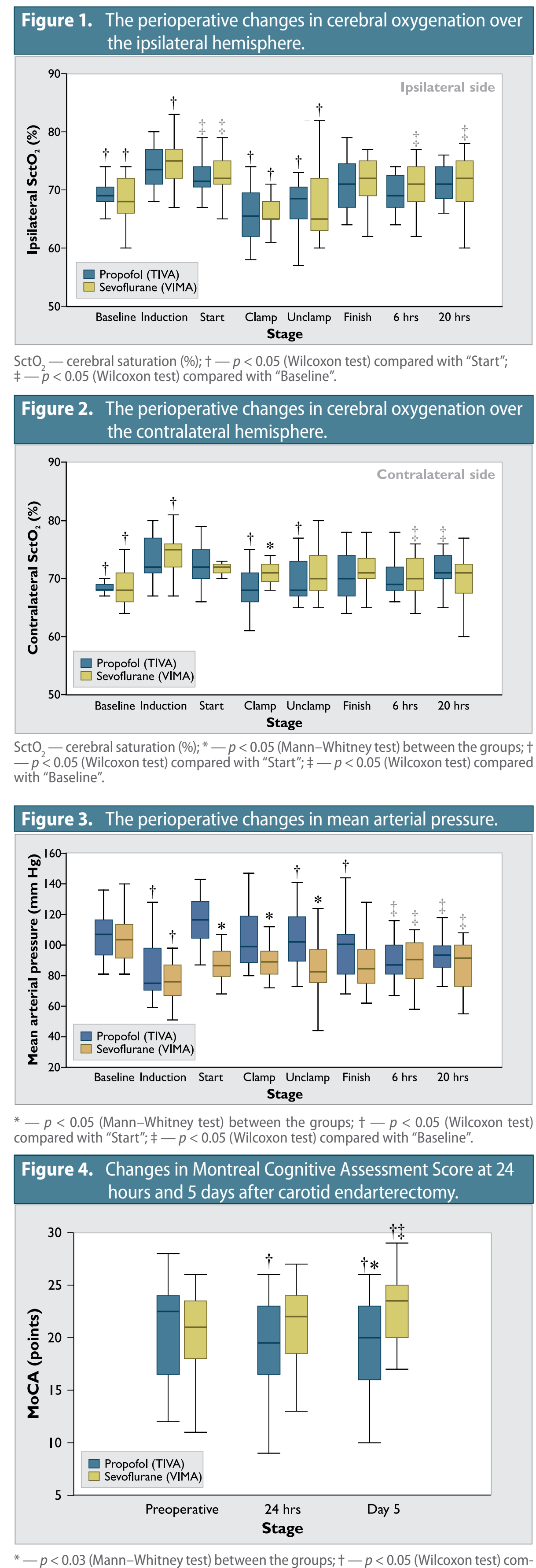

serve any intergroup differences in $\mathrm{SctO}_{2 \text { IPSI }}$ (Figure 1). In both groups, $\mathrm{SctO}_{2 \mathrm{IPSI}}$ significantly decreased at the clamping and unclamping of carotid artery compared with values at start. In the VIMA group, $\mathrm{SctO}_{2 \text { IPSI }}$ at 6 and 20 hrs significantly improved compared with preoperative ("Baseline") values. In contrast, the values of $\mathrm{SctO}_{2 \mathrm{CONTR}}$ instantly after the primary carotid clamping were significantly higher during sevoflurane anaesthesia $(p<0.05)$ despite lower mean arterial pressure in the VIMA group at this particular time-point (Figures 2, 3).

We observed better cognitive function by Day 5 after sevoflurane VIMA compared with the propofol TIVA group: the MoCA values were 24 (20-25) pts. vs. $20(16-23)$ pts., respectively $(p=0.028)$. In addition, the patients of the TIVA group demonstrated significant intragroup reduction of MoCA values $24 \mathrm{hrs}$ after the uneventful intervention $(p<0.01)$ (Figure 4).

In part, our results are controversial with the very similar study of Kalimeris K. et al. $(2013)^{2}$ shown better early cognitive function in propofol TIVA compared with volatile maintenance of anaesthesia with sevoflurane. This discrepancy can be explained by the differences in induction approach and timing of postoperative assessment of $\operatorname{cog}$ nitive functions.

\section{Conclusions}

In elective CEE, volatile induction and maintenance of anaesthesia with sevoflurane might preserve blood flow and oxygenation in the contralateral hemisphere and improves the postoperative cognition as compared with propofol total intravenous anaesthesia.

\section{Acknowledgements}

We thank the personnel of the Vascular Surgery Department, Municipal Hospital \#1 of Arkhangelsk.

\section{References}

1. Heyer EJ, DeLaPaz R, Halazun HJ, et al. Neuropsychological dysfunction in the absence of structural evidence for cerebral ischemia after uncomplicated carotid endarterectomy. Neurosurgery 2006; 58: 474-480.

2. Kalimeris K, Kouni S, Kostopanagiotou G, et al. Cognitive function and oxidative stress after carotid endarterectomy: comparson of propofol to sevoflurane anesthesia. J Cardiothorac Vasc Anesth 2013; 27: 1246-1252.

Shmelev VV, Neimark MI. Prevention of cognitive disorders in postoperative period after carotid endarterectomy. Anesteziol Reanimatol 2013: 4: 9-14. 